\title{
Higher education and its communities: Interconnections, interdependencies and a research agenda
}

\author{
Ben Jongbloed $\cdot$ Jürgen Enders $\cdot$ Carlo Salerno
}

Published online: 18 April 2008

(C) The Author(s) 2008

\begin{abstract}
Universities everywhere are being forced to carefully reconsider their role in society and to evaluate the relationships with their various constituencies, stakeholders, and communities. In this article, stakeholder analysis is put forward as a tool to assist universities in classifying stakeholders and determining stakeholder salience. Increasingly universities are expected to assume a third mission and to engage in interactions with industrial and regional partners. While incentive schemes and government programmes try to encourage universities to reach out more to external communities, some important barriers to such linkages still remain. To fulfil their obligation towards being a socially accountable institution and to prevent mission overload, universities will have to carefully select their stakeholders and identify the 'right' degree of differentiation. For the university, thinking in terms of partnerships with key stakeholders has important implications for its governance and accountability arrangements. For the future of the universities we foresee a change towards networked governance and arrangements to ensure accountability along the lines of corporate social responsibility. In order to further explore some of these concepts and to empirically investigate the tendencies suggested here, this article proposes an ambitious research agenda for tackling the emerging issues of governance, stakeholder management and higher education's interaction with society.
\end{abstract}

Keywords Stakeholder analysis - Third mission · Governance ·

Community engagement

B. Jongbloed · J. Enders $(\bowtie)$

Center for Higher Education Policy Studies (CHEPS), School of Management and Governance,

University of Twente, PO Box 217, 7500 AE Enschede, The Netherlands

e-mail: j.enders@cheps.utwente.nl

B. Jongbloed

e-mail: b.w.a.jongbloed@cheps.utwente.nl

C. Salerno

Government Accountability Office (GAO), Washington, DC, USA

e-mail: salernoc@gao.gov 


\section{Introduction}

This article reflects on the interconnections and interdependencies between higher education, society and economy. Higher education is interacting with an increased number and variety of communities and each of these has its particular demand on the higher education sector. This has resulted in new and revised relationships between higher education institutions (in short: universities) and their external communities or stakeholders. These relationships have local, regional, national and international ingredients (e.g. Dill and Sporn 1995; Castells 1996; Clark 1998; Huisman et al. 2001; Enders 2004; OECD 2007). Such interconnections and interdependencies relate to both the external functions of higher education, for example in terms of the economic and social functions it carries out, and the services in terms of teaching, research and knowledge transfer. The economic expectations placed on higher education reflect both the knowledge and skills needs of workers in modern knowledge-based economies and the demands for relevance in research and knowledge creation that underlie the successful development of these economies (Castells 1996; Etzkowitz and Leydesdorff 1997; Enders and Fulton 2002). The social expectations placed on the university reflect the centrality of educational credentials to opportunity and mobility structures in modern societies and the access to such structures among, for example, different social classes, ethnic groups and geographical regions (Shavit and Blossfeld 1993; Tight 2003).

We will place this topic within the discussion on the wider role and function of the university. The discourse on the role —or the idea (see Rothblatt 1997) — of the university has shifted since the post-war years (Geiger 1993). In order to secure their place in the modern, knowledge-based economy, universities everywhere are being forced to carefully reconsider their role and the relationships with their various constituencies, stakeholders, or communities. This, in turn, translates into identifying stakeholders, classifying them according to their relative importance, and, having done that, establishing working relationships with stakeholders. How a university (or indeed its many constituent parts) proceeds to identify, prioritise and engage with its communities reflects the evolution of the university. One may argue that the outcome of this process of stakeholder engagement will have important implications for the university's chances for survival. A careful study of such processes, the forces that drive them and their impacts on the internal workings of the university seems to be both timely and warranted.

Such a study is also timely since the contemporary university suffers from an acute case of mission confusion. Many universities are taking on similar ideals while suboptimally allocating their scarce human and physical capital. The multitude of communities (both traditional and emerging) with which universities now engage demand a more clearly articulated strategy for understanding and managing stakeholder (i.e. community) relationships. One plausible consequence is that such demands will require a new governance and accountability approach, highly professional management and a rethinking of the university's business concept - that is the way in which the university creates value and how it assesses its value (de Boer et al. 2007). Some evidence may be found in the many specialised functions and management systems that one sees emerging to handle the universities' response to external demands. Such functions appear to play a bridging role between the university and particular communities. Understanding universities as complex social actors is key, not just to build more efficiently functioning universities, but also for identifying the unintended consequences and possible pitfalls that may emerge through the adoption of new approaches. An engaged university may be a driver of innovation but it may also be one that fosters the commodification of higher 
education, placing the private good character of higher education above the public good (Enders and Jongbloed 2007).

\section{On communities, stakeholders and missions}

As observed by Georges Haddad (quoted in Neave 2000, p. 29), the term university finds its origin both in legal Latin "universitas", meaning "community", and in classical Latin "universus", meaning "totality". These days, the university's communities indeed may be said to encompass a great number of constituencies. Internally they include students and staff (the community of scholars), administration and management, while externally they include research communities, alumni, businesses, social movements, consumer organisations, governments and professional associations. Geographically, the university's varied communities tended to be in near proximity to its physical campus. Today though, advances in information technology have made it possible for even the remotest higher education institution to tap into communities on the other side of, or even dispersed around, the entire globe.

Implicit in this description of communities are notions of relationships, environment, expectations and responsibilities. A particular community is relevant for the university only if there is some expectation on both sides (i.e. the university and the community) that some service can be rendered or a mutually beneficial exchange (a transaction) can take place. This illustrates that the concept of community is close to the stakeholder concept. The stakeholder concept originates from the business science literature (Freeman 1984). The concept may be traced back to Adam Smith's "The Theory of Moral Sentiments". Its modern use in management literature comes from the Stanford Research Institute that in 1963 introduced the term to generalise and augment upon the notion of stockholder as the only group to whom management need be responsive. Originally, the stakeholder concept was defined as "hose groups without whose support the organisation would cease to exist" A more modern definition of stakeholders is "any group or individual who can affect or is affected by the achievement of the firm's objectives" (Freeman 1984, p. 16). Freeman argues that business organisations should be concerned about their stakeholders' interest when making strategic choices.

The communities - or stakeholders - that a university is expected to respond to consist of organisations and groups of individuals. They will often posses a number of common characteristics. Most stakeholders have a human scale; the members of a group of stakeholders often share a common identity (in the sense of belonging together, or sharing a common culture or location) with certain shared obligations both on the side of the members as well as on the side of the university. In higher education, the most important, or core, community would be the students. Another important stakeholder is the government. As the main funder of higher education it would like to ensure that higher education meets the interests of students and society in general.

While we may agree that government is an important stakeholder, this by no means suggests that government represents a well-defined and clear-cut influence on higher education institutions. While the basic function of higher education may be seen as being responsible for the transmission of knowledge to the younger generation and the advancement of fundamental knowledge, the fact is that today higher education interacts with many other public policy domains. This implies that 'government' represents many other communities of interest. It is not a unitary stakeholder. Next to the area of training and research, higher education interacts with areas like health, industry, culture, territorial 
development and the labour market. Therefore, other ministries, next to the Education Ministry, affect the higher education agenda. Each of these ministries represents different stakeholder groups. In fact, one may argue that higher education is in the unique position of being the sector where the various demands are integrated-where it is all "joined up" (Benneworth and Arbo 2006, p. 91).

In other words, higher education institutions have a distinctly 'public' character or responsibility (Neave 2000, p. 2) to society. To meet this public responsibility, they have historically received generous amounts of government funding and, at least in some countries, a commensurately good deal of institutional and academic autonomy. Society, through laws and government, defines their responsibilities. Today, their social responsibility (Neave 2000) is closely scrutinized. The basic functions that higher education institutions perform are going through a process of change. Their teaching and research functions are being reassessed, in particular with an eye upon the contribution they make to the social-economic well-being of their environment-be it the region, the nation or a collective of nations (e.g. the European Union).

Higher education is not only expected to deliver excellent education and research, it also has to deliver those outputs in ways, volumes and forms that are relevant to the productive process and to shaping the knowledge society. This has been characterized by some as a fundamental change in the social contract between science and higher education institutions, on the one hand, and the state on the other, with the latter now having much more specific expectations regarding the outputs produced vis-à-vis the return on the public's investment (Guston and Keniston 1994; Neave 2006).

As far back as 1973 there were discussions about changing the social contract between higher education and society (ILO 1975). In addition to the transmission and extension of knowledge, universities at the time were being called upon to:

- play an important role in the general social objective of achieving greater equality of opportunity;

- provide education adapted to a great diversity of individual qualifications, motivations, expectations and career aspirations;

- facilitate the process of lifelong learning

- assume a public service function, i.e. make a contribution to the solution of major problems faced by the local community and by society at large, and participate directly in the process of social change (OECD-CERI 1982, p. 10).

It is striking to see how relevant this 25 -year old list still is in today's discussions on the role of the university. Improving access options for a diverse student population by having universities offer an increased variety of educational opportunities is now high on many governments' higher education agendas. So too is lifelong learning-at least in words. Higher education's contribution to innovation-be it economic or social innovation-has been a distinct theme now for more than a decade.

Present day universities are forced to be in constant dialogue with their stakeholders in society. This may lead to a number of fundamental changes in the relationship between the universities and their environment. Co-ordination mechanisms, as well as their counterpart: accountability mechanisms, may need to be re-asserted. Accountability will manifest itself in new and complex forms. In their education and research tasks, the universities will continue to have an obligation to demonstrate quality, efficiency and effectiveness, not just to those in national administration which have the legal and historic responsibility for exercising official oversight, but increasingly so to a wider range of stakeholders. To this 
end, many higher education systems have included external personalities, laymen or regents in their various governing bodies (Trow 1996).

However, the notion of stakeholders, as opposed to lay representative or external personalities, redefines the conduct, role, responsibilities and thus the nature of the 'interface' between higher education and society. The term stakeholder points to a major shift in the roles assigned to those who participate in higher education institutions' decision-making as representatives of external society, just as it points to an equally major shift in the obligation to render accounts to the general public or to agencies acting in its name.

The consequences for the higher education establishment of the rise of the Stakeholder Society have been explored indirectly as sub-components of inquiries into diversification of funding sources, as a concomitant to the overhaul of higher education governance and decision-making procedures, as a desirable outcome of contractualisation, or as an aspect of relations between higher education institutions and their region. Given the emphasis that public policy now places upon revenue generation as a pointer to the entrepreneurial dynamism of higher education institutions, it is to be expected that individual establishments have put in place formal structures with the specific purpose of dealing with stakeholders, in addition to any changes in formal governance structures intended to increase the weight of societal interests.

The issue of representation of stakeholders is directly related to that of responsiveness and legitimacy. As stated above, in recent years one can observe a change in the perception of the place the university occupies in the community. The universities' standing, prestige and reputation continue to be determined by internal, disciplinary values and scholarly attainment. However, they are also intimately associated in official thinking with the appropriateness of the services rendered to the community - where that community can be local, regional, national, or even inter-national. This change in the mission, role and tasks laid upon universities affects the relationships between the university and its environmental constituencies. In short, the legitimacy of higher education in society will increasingly be a direct function of the nature, quality and evolving ties with the Stakeholder Society.

The mission of an individual higher education institution is generally stated in terms of its teaching, research and community service obligations. Though a mission statement is usually general in its wording, it is a reflection of how the institution views its expected contributions to society. In the business world, mission statements translate into business plans, which translate into strategies, policies and budgets-the tools for achieving the organisation's goals. The mission or vision of the organisation may be defined by means of the existential questions listed in Table 1.

The shaping of a mission takes place in an institutional setting-in an environment that may be different for different institutions. It is important to acknowledge that universities are embedded in a national as well as a regional system-some in the neighbourhood of a large industry, others in more remote areas. Out of this, different types of universities emerge, ranging from research-intensive to teaching intensive, with a technological (or

Table 1 Defining the mission-key questions

\begin{tabular}{ll}
\hline Facts & Ambitions \\
\hline What is our business? & What should be our business? \\
Who are our students? & Who should be our students? \\
What is our environment? & What opportunities are there? \\
What are our resources? & How should we deploy our assets? \\
\hline
\end{tabular}


some other subject-specific) character or a multi-faculty composition. Some higher education institutions are particularly committed to the goal of reducing social and spatial inequalities. Others may see research excellence as their top priority. It is also important to note that for a university the choice of mission or profile and, consequently, how the institution relates to its stakeholders, is never shaped entirely by its communities, but also very much path dependent. History and geography - in other words, institutional contingency and regional contingency-will also shape the relationships a university has with its stakeholders.

The key message here is: there is diversity of stakeholders, of higher education institutions, and their missions. As the direct role of the state is reduced and both the autonomy of the individual universities and the role of the market increases, the university becomes more and more integrated in society. The potential downside of this trend is that universities may become fragmented and that the civic responsibility they have to society comes under threat. Steering universities out of this dilemma and preventing them from being overburdened by stakeholder claims requires careful management. In the next section we will introduce the idea of stakeholder management as an approach to steer higher education institutions in a more structured way.

\section{Stakeholder theory}

The previous section illustrated that for the university to be an effective institution in an increasingly complex environment, it is not just a matter of generating sufficient income to remain in business, but that it is equally essential that the institution proves its relevance to society and the various entities in society that it regards as important (Jongbloed and Goedegebuure 2001). The identification of the main stakeholder groups is not straightforward or simple though. In business, both employees and customers qualify as stakeholders and some have argued that universities share this peculiar behaviour (Winston 1999). However, different employees and different customers can have different stakes in, or a different influence on, organisations. The stakeholder approach to management (Freeman 1984) may be a useful tool that assists organizational actors in dealing with their environments through selectively perceiving, evaluating and interpreting stakeholder attributes. Mitchell et al. (1997) use Freeman's stakeholder concept and provide an approach that helps to identify "who or what really counts" and to assess the degree to which managers pay attention to their stakeholders.

Table 2 presents the various stakeholder categories of a higher education institution. It provides examples of specific groups that exert pressure on a higher education institution's actions, behaviour and policies. The table lists the actors or groups of actors to which a university may pay attention. Surely, the degree to which this actually is the case will vary.

In order to increase their pressure on the institution, some stakeholders may build coalitions with others in order to maximise their collective gains. In explaining the degree to which organisations give priority to competing stakeholder claims, Mitchell and colleagues formulated their theory of stakeholder salience. This theory distinguishes between three attributes of stakeholders (see Mitchell et al. 1997, p. 869):

1. The stakeholder's power to influence the organisation-here power defines a relationship among social actors in which one social actor, A, can get another social actor, B, to do something that B would not have otherwise done. In the case of higher 
Table 2 Stakeholder categories and constitutive groups

\begin{tabular}{|c|c|}
\hline Stakeholder category & Constitutive groups, communities, stakeholders, clients, etc. \\
\hline Governing entities & $\begin{array}{l}\text { State \& federal government; governing board; board of trustees, buffer } \\
\text { organisations; sponsoring religious organisations }\end{array}$ \\
\hline Administration & President (vice-chancellor); senior administrators \\
\hline Employees & Faculty; administrative staff; support staff \\
\hline Clienteles & $\begin{array}{l}\text { Students; parents/spouses; tuition reimbursement providers; service partners; } \\
\text { employers; field placement sites }\end{array}$ \\
\hline Suppliers & $\begin{array}{l}\text { Secondary education providers; alumni; other colleges and universities; food } \\
\text { purveyors; insurance companies; utilities; contracted services }\end{array}$ \\
\hline Competitors & $\begin{array}{l}\text { Direct: private and public providers of post-secondary education } \\
\text { Potential: distance providers; new ventures } \\
\text { Substitutes: employer-sponsored training programmes }\end{array}$ \\
\hline Donors & $\begin{array}{l}\text { Individuals (including trustees, friends, parents, alumni, employees, industry, } \\
\text { research councils, foundations) }\end{array}$ \\
\hline Communities & $\begin{array}{l}\text { Neighbours; school systems; social services; chambers of commerce; special } \\
\text { interest group }\end{array}$ \\
\hline $\begin{array}{r}\text { Government } \\
\text { regulators }\end{array}$ & $\begin{array}{l}\text { Ministry of Education; buffer organisations; state \& federal financial aid agencies; } \\
\text { research councils; federal research support; tax authorities; social security; Patent } \\
\text { Office }\end{array}$ \\
\hline $\begin{array}{l}\text { Non-governmental } \\
\text { regulators }\end{array}$ & $\begin{array}{l}\text { Foundations; institutional and programmatic accrediting bodies; professional } \\
\text { associations; church sponsors }\end{array}$ \\
\hline $\begin{array}{l}\text { Financial } \\
\text { intermediaries }\end{array}$ & Banks; fund managers; analysts \\
\hline Joint venture partners & lliances \& consortia; corporate co-sponsors of research and educational se \\
\hline
\end{tabular}

Source: Adapted from Burrows (1999)

education, one can think of the growing pressure from students, parents and legislators to force universities to adopt more cost-conscious operating principles.

2. The legitimacy of the stakeholder's relationship with the organisation-legitimacy is defined as a generalised perception or assumption that the actions of an entity are desirable, proper, or appropriate within some socially constructed system of norms, values, beliefs and definitions. Today, the university's traditional stakeholders (e.g. students and governments) have been supplanted by, amongst others, local industry.

3. The urgency of the stakeholder's claim on the organisation-urgency represents the degree to which stakeholder claims call for immediate action. A good example would be the greater emphasis put on research in health/life science fields at the expense of research in other scientific areas.

For mapping the relationships with their external and internal communities (constituencies, stakeholders, etc.) these three attributes can be of use for institutional managers. They may help identify which are the crucial stakeholders to deal with and, therefore, which relationships are to be maintained.

The presence or absence of the attributes power, legitimacy and urgency translates into a simple typology of stakeholders. Classes of stakeholders can be identified by the possession (or attributed possession) of one, two, or all three of the attributes. Figure 1 below (from Mitchell et al. 1997, p. 874) shows that stakeholder classes differ in terms of their degree of salience, or, in other words, the degree to which institutions give priority to competing stakeholder claims. Stakeholder salience is positively related to the cumulative 
power of the three attributes that the managers perceive to be present, which in turn triggers managerial actions. It is also important to note that power, legitimacy and urgency can change - they are not static, but dynamic. This implies that particular stakeholders can move from one class to another by gaining or losing particular attributes. Figure 1 shows seven classes of stakeholders; the eighth constitutes the non-stakeholders. The seven classes can be subdivided into three groups:

Latent stakeholders (classes 1, 2, 3) possess only one attribute:

- class 1: dormant stakeholder (the relevant attribute is power)

- class 2: discretionary stakeholder (legitimacy)

- class 3: demanding stakeholder (urgency)

Expectant stakeholders (classes 4, 5, 6) possess two attributes:

- class 4: dominant (power \& legitimacy)

- class 5: dangerous (power \& urgency)

- class 6: dependent (legitimacy \& urgency)

Definitive stakeholders possess all three attributes:

- class 7: definitive (power, legitimacy, urgency).

Stakeholder salience is low for the group of latent stakeholders, moderate for expectant stakeholders and high for definitive stakeholders.

Stakeholder theory may be useful in higher education to help explain the attention paid to the various communities in the environment and the relationships between a university and its communities. Since the government is the most important source of funds for universities it is a definitive stakeholder. However, other stakeholders are moving from a latent to an expectant status. For example, increased demand for retraining and retooling their employees moves businesses and employers' organisations toward the definitive stakeholder status. The emergence of the new, knowledge-driven economy has added the attribute urgency to the attributes legitimacy and power that this stakeholder already possessed because of the representation that businesses and industry have on boards of trustees, faculty boards and accreditation committees. Combined with the fact that an increased share of universities' funds come from contract research and that government

Fig. 1 A stakeholder typology

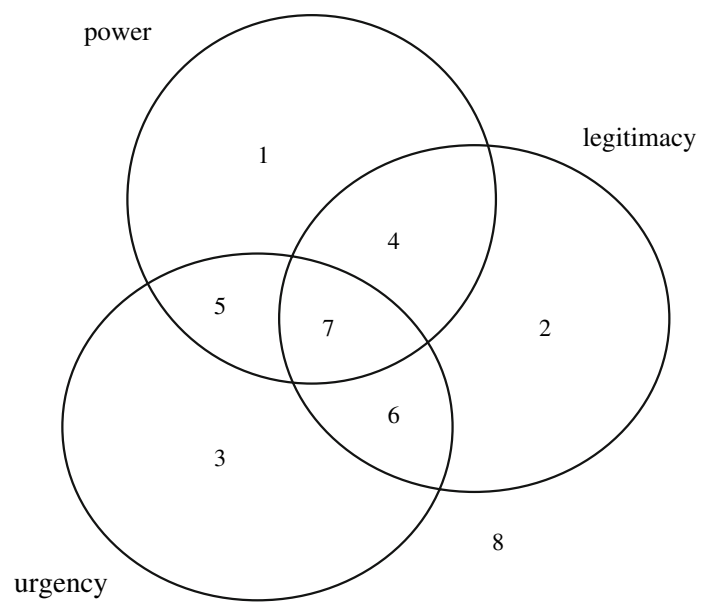


expects universities to contribute (through teaching and research) to economic development and society in general, this transforms some businesses into definitive stakeholders.

Applying this perspective to a higher education setting adds another dimension. Given the characteristics of the university as an organisation-professional domination, fragmentation of decision-making and diffusion of power-stakeholder identification takes place not only at the central institutional or management level but at other levels as well. So the identification and the subsequent salience of stakeholders may also very well differ depending on whose perspective is taken as the starting point. This implies that the matrix presented in Table 2 in fact ought to be three dimensional, the third axis representing universities' internal actors. In terms of institutional management this adds to the complexity of strategic decision-making. Not only must attention be paid to the identification of external stakeholders (by the central managers), also the possibly different outcomes of similar identification processes within other parts of the institution need to be taken into account. One logical consequence of this is the need for a fairly continuous dialogue between the different constituents (internal stakeholders!) within the institution on the implications of this for the overall strategy.

If the university identifies a particular stakeholder as 'dangerous' (in terms of the typology presented earlier) one strategy might be to intensify the relationship by engaging in a specific form of strategic partnership. There are many manifestations of partnerships and strategic alliances, from corporate venturing and licensing to franchising, all the way to downright mergers and acquisitions. The alliances differ according to how interwoven the organisation and its financing is (see Huyzer 1990).

Being discipline-based, the university's academic departments often show more affinity to similar departments at other universities than to the departments in their own institution (Alpert 1985). Researchers first and foremost see themselves as belonging to a disciplinary community and often seek alliances, recognition and support in their disciplinary fieldthat is, among their peers. Strategic partnerships between university departments therefore are not confined to a university's immediate region, but increasingly extend even beyond national borders.

Where the teaching and learning function of the university is concerned, regional firms may obviously form a first candidate for partnerships. Local and regional firms provide internship (student placement) opportunities for students and express a demand for retraining and re-skilling their employees (see Goddard et al. 1994; Garlick 2000).

As Table 2 has shown, the stakeholders of a university are many. They may be classified as internal or external; individual or collective; academic or non-academic. The community of scholars may be seen as an important internal stakeholder category. The academic community represents the nucleus of scientific production. It is the basic internal constituency without which the university cannot function properly. While some may argue that this part of the scientific system would need to be detached as much as possible from external influences, there are fields like law, medicine and engineering where the academics are in continuous dialogue with professional associations to uphold the relevance and legitimacy of their field.

Another key stakeholder category is the students. Since higher education is a customerinput technology (Rothschild and White 1995), this observation is all the more true. Students, being the customers of higher education institutions, are an essential input into the teaching process. It is not only through lecturers, professors, or other efforts of universities that students are educated, but also through the contributions of fellow students. Students are partly educated through their peers and the quality of peers co-determines the 
outcome of learning. When it comes to engagement with external communities, students drive a lot of the activities here.

External stakeholders also can come in many shapes. When the university regards their claims as important, their voice may be heard via external representatives in the university's internal decision-making bodies. An interesting question here is whether the external representatives are representing themselves or representing a wider group. For instance, who can speak for external stakeholders such as the small and medium-sized enterprises? This touches on the individual versus collective dimension. Later on in this article we will return to this issue when we discuss higher education governance reforms.

When it comes to stakeholders, one can observe a growing importance of the nonacademic part of academe. The role played by the finance department, the human resources/career services department, the technology transfer office, the international relations office, or the office for fund raising is becoming increasingly important. These are influential gatekeepers between the university and its external stakeholders; acting also as a bridge between the management and the academic staff. In many institutions, these functions undergo a professionalisation and have emerged as an important internal constituency to be reckoned with.

\section{Community engagement, the third mission}

The intensification of exchange between universities and their stakeholders invokes a different kind of commitment that extends well beyond financial relations or fiscal responsiveness. Academics and policymakers have long made reference to higher education's third mission, yet it remains an ethereal component of what higher education actually does. It is supposed to be a third role beyond teaching and research that centers specifically on the contribution to regional development (Goddard 1999; Chatterton and Goddard 2000; Charles and Benneworth 2002; OECD 2007). Some call it outreach while others call it community service. As third mission activity often covers everything besides traditional teaching and traditional research, this does little to help frame it as a task that can be shaped.

The basic problem with analyzing the third mission is that it entails a good deal of mission overlap. Concepts like lifelong learning or professional development often translate into the provision of short- or highly-specialized courses that meet the needs of specific groups of individuals. Nevertheless, it is still an education activity in its most basic form. In the same way, concepts like industry-university partnerships or commercialization translate into mechanisms that exploit knowledge capacity or maximize financial rewards so as to promote further innovation. Again though, both are rooted in the exploitation of discovery, which is research in its most basic form. In short, one might argue that the third mission is not so much its own mission as it is a reflection of the unique stakeholders that fall outside of the traditional purview.

Today, a greater weight is placed upon the commitment to community service in terms of providing training and research, investigation and advice, as well as such services as consultancies, technology transfer, lifelong learning and continuing education (Neave 2000). New partnerships at local and sub-national regional level also follow from the need to diversify support and funding. As universities seek to increase external revenue sources, they develop closer links to industry and demonstrate entrepreneurship through the setting up of science parks, spin-off firms and business ventures. The potential role that universities can play as drivers of economic development is well espoused in OECD reports 
(2007) and Communications from the European Commission (2003). They increasingly are incited to provide teaching and research that is nationally and regionally relevant or applicable. The growing chorus over the role of universities as economic engines has elevated the debate beyond rhetoric and into the realm of policy actions, particularly in the United States. Paytas et al. (2004) offer a comprehensive literature review of studies on universities' abilities to stimulate regional economic development.

The linking up of universities and their regions through teaching and research has pushed engagement as another dimension on which these institutions are judged by governments as well as other stakeholders. Engagement here involves a set of activities through which the university can demonstrate its relevance to the wider society and be held accountable. The rise of a community engagement agenda offers universities a range of possibilities to function as sites of citizenship. These include contributing to community social and economic infrastructure, the building of social capital, contributing to the resolution of local issues, supporting equity and diversity, and education for democratic citizenship. In other words, universities are playing — and according to some should playa broader and more visible role in the educational, social and economic well-being of local communities and the nation. The third mission therefore consists of a knowledge transfer function as well as a more general community function. It is an umbrella term that refers to a wide variety of principles and strategies for economic and social development.

This makes community engagement and third mission difficult to separate from the traditional teaching and research activity - they cannot be put in a separate box. When engagement is high on a university's agenda, the challenge for those in charge of the university is to achieve a situation where community engagement is realised through the core activities of teaching and research and not have it regarded as a residual activity. The goals of engagement and third mission are less about relationships and more about partnerships, where the focus is on mutually beneficial relationships. This implies a different type of relationship compared to one that is focussing on outreach, where the balance of power tilts towards the academic entity.

\section{Expanding the research mission: interaction with business and communities}

In the wake of the Lisbon agenda, a lot of attention has been given recently to government policies and incentive schemes encouraging universities to become more entrepreneurial and to interact more closely with their outside (business) world, thereby stimulating the innovative capacity of a country/region. An often heard concern is that the interaction between the public knowledge infrastructure and society is not optimal (known as the knowledge gap). Among other things, this has resulted in an increased attention for relevance as a criterion in the assessment of academic research (see Jongbloed 2006).

The demands for a more intense interaction originate partly from within the universities and the domain of science and partly from outside the scientific community. With respect to the latter, the trend of interacting with business and community is partly the outcome of efforts to seek compensation for decreasing state funding. Yet another trend that is supposed to contribute to closer interactions lies in the changing modes of knowledge production (Gibbons et al. 1994). Mode 2 research involves greater external connectedness, collaboration across organizational boundaries and more frequent interaction between public research organisations and organisations from business and industry. Such forces certainly challenge our thinking about a well-established order for science and research in proposing a qualitative transformation of its role and functioning in society. They also have 
led to a debate about the empirical evidence and the explanatory power of the Mode 2 model (Weingart 1997; Shinn 1999; Gläser 2000).

What is clear though is that the linear model of technology transfer is gradually replaced by a network model, meaning that contract research and consultancy services are taking place next to collaborative work within strategic alliances. Many institutions have developed closer relationships with the external world and a more applied approach to research. Reach-out units are established and (financial) incentives are introduced alongside reforms in governance and organisational structures in order to improve the links between public sector research and the business sector. These changes have made the traditional picture of higher education fuzzier around the edges.

There are many forms of higher education-business interaction; some of a formal, others of an informal nature. The dominant interaction channels are research publications, public meetings and conferences, research contracts, research staff acting as consultants, sharing of equipment, and students doing internships or on-the-job training. However, after having learned that intellectual property rights may represent commercial wealth, universities have become more aggressive on the market for knowledge and developed new linkage structures with industry. From 1980 on, more formal, contract-based relationships-joint equity-based ventures (i.e. spin-offs) or co-operative (public-private) ventures as well as patents-have become more common. Many universities and colleges nowadays have their own intellectual property offices or technology licensing offices and professionally manage their intellectual property rights. They have also set up campus-based industrial extension services that are primarily aimed at the local and national business community as well as other facilitation mechanisms to increase university-industry interaction (see Chatterton and Goddard 2000). Some universities have developed dedicated independent structures such as science parks and incubators to facilitate academic start-up firms and newly established licensees of university patents. This is going along with initiatives to encourage contract research, consulting services by faculty. Facility sharing is another interaction mechanism, where firms are charged an annual fee in exchange for access to state-of-the-art laboratories and know-how. And, finally, universities and industries have also joined in new organisations like university-industry shared research centres. Through strategic alliances and research consortia, university and industry aim at collaborative $\mathrm{R} \& \mathrm{D}$ and the joint commercialisation of R\&D-products.

The exact type of research-based interaction between universities and their non-university partners heavily depends on the discipline in question. Medicine, life sciences and engineering show a different type of interaction compared to arts and humanities and social sciences. It is also important to note that the issue is not just a demand side pull phenomenon, but also a matter of science push. University graduates and staff are still regarded as the prime and most effective technology transfer mechanism. The number, quality and level of the graduates working in a particular firm or branch of industry heavily determine the intensity and effectiveness of the knowledge flows between university and research-oriented firms (see Cohen et al. 2002). In addition, the spatial configuration of the partners from university and industry is essential-networking opportunities are greater when partners are located in the same area.

However, not all policy efforts and institutional reforms to encourage greater interaction between higher education institutions and their stakeholder communities are necessarily warranted, even in the face of intuitive appeal. The Bayh-Dole Act (1980) provides an excellent example, as it gave academics whose research was being funded by federal dollars newfound flexibility to reap the financial rewards of their work. Politicians have long trumpeted Bayh-Dole's success as an example of well-developed policy and the 
rhetoric has led some to suggest that similar legislation would be useful or even necessary to strengthen links between higher education institutions and industry in European countries (Mowery and Sampat 2005). In reality though, the Act is frequently given too much credit. Commercializing university research in the US has been done since the beginning of the 20th Century and was well underway prior to 1980. What is more, most US government departments and agencies already had their own regulations on faculty patenting of federally-funded research by the early-1970s. Bayh-Dole did not open the floodgates for American university scientists to suddenly patent their own research findings nor did it suddenly encourage faculty members to pursue stronger industry-university interactions. All it really did was consolidate the wide array of existing arrangements into one single piece of legislation. As some researchers suggest, faculty patenting and university-industry research partnerships in general would have likely experienced the same growth that has taken place since the early-1980s, without the Act (Mowery et al. 2001). A more likely explanation for the growth was the parallel development of computing power (and use) and the surprising success of life sciences research in creating marketable pharmaceutical products for an ageing population.

Turning to the demand side of the equation - to the demands of business and industry for the outputs of academic research-it needs to be noted that this demand will have to be properly articulated for any interaction or knowledge transfer to take place at all. In particular when it comes to the sector of small and medium-sized enterprises (SME), the business partner may not possess the ability to clearly formulate his knowledge demand. Many SME partners also will not have sufficient financial resources to access academic knowledge - in fact they may even lack information about what universities have to offer. However, a survey of some 400 industry-university partnerships conducted by Lee (1996) shows that those businesses that do work with universities mention the following reasons: (1) access to new research, (2) development of new products, (3) maintaining a relationship with the university, (4) obtaining new patents, and (5) solving technical problems. In stark contrast, the two top priorities for university participants in industry-university partnerships were: (1) obtaining funds for research assistance, laboratory equipment and their personal research agendas, and (2) being able to field test theory and empirical research. Surveys like these point at conflicting motives at both sides. If we accept industry's longstanding reluctance to exploit university research in favour of other sources (Cohen et al. 2002) and the polarized expectations of both partners, then developing such linkages will require considerable effort not only from industry but also from the higher education institutions and, more specifically, their faculty members.

In the UK, the Higher Education Innovation Fund (HEIF) financially supports higher education institutions in knowledge exchange and productive interactions with business, public sector organisations and the wider community, for the benefit of the economy and society. The majority (about 75\%) of the HEIF funding is allocated by formula to universities on the condition that they submit plans for its use. A smaller amount (approximately 25\%) is available through a competition, for particularly innovative projects. The formula funding part is partly driven by data collected in a survey known as the Higher Education-Business and Community Interaction (HE-BCI) survey (see http://www.hefce.ac.uk/reachout/hebci/). The UK though is quite exceptional in having a funding stream for third mission activities. Other countries (e.g. Australia and the Netherlands) are contemplating similar initiatives, but struggle with finding adequate indicators to objectively underpin third stream funding allocations.

If indicators of university-industry interaction are to be used for informing the funding decisions the Matthew effect may arise, meaning that there is a risk of reinforcing inherited 
performance. Institutions that do well in terms of interaction will receive more funding, whereas those that have not yet built up a demonstrable track record in third stream activity get less. In particular, if policy makers are interested in encouraging institutions to become actively engaged in knowledge exchange with the wider environment, an indicator-driven formula may not be the most appropriate approach. Instead, a contract-based-that is: a forward-looking approach, using leading indicators instead of backward looking indicators-may be more suitable.

\section{Barriers to community engagement}

The previous section may have given the impression that interaction with industry and engagement with the community is something that every university should be involved in. However, from day-to-day practice we know that universities mostly engage in interactions with their traditional stakeholders, such as students, fellow researchers, funding organizations, research sponsors, et cetera. Clearly, there are barriers that prevent the wider type of community engagement, including working with industry. Since the behaviour of organizations is to a large extent shaped by their institutional environment, it is natural to pay attention to the set of rules, regulations, quality assessment procedures, accountability standards and incentive (e.g. funding) schemes that affect behaviour. Such framework conditions may be identified on the national (or system) level, but surely the institutions themselves also shape their own internal framework conditions (Joanneum Research 2001).

Many of the barriers that stand in the way of an active interaction can be traced back to historical origins and regulatory characteristics. The question is what is the dominant influence in the environment that shapes interaction? Is it the government, is it competition, is it the region? Surely, the situation is different from country to country and-to some extent-from institution to institution. To increase community interaction by universities, the institutional barriers need to be studied. Three types of barriers may be identified:

1. the determination of the research agenda and the educational offerings of universities;

2. the internal reward structure of universities;

3. the lack of an entrepreneurial culture in universities.

Ad 1. Most universities are structured along the lines of academic disciplines. Traditionally, the developments in the disciplines and the scientific criteria maintained in the disciplines determine the research agenda and the contents of the curriculum. The way in which financial resources are allocated across and within disciplines determines to a large extent the research portfolio and the curricular options. Interaction between the various disciplines is not as frequent as it perhaps should be, given the calls made to increase flexibility and interaction in terms of teaching and research. In other words, the public research agenda and the supply of educational programs may be very different from the demands expressed by the private sector. There may be a quantitative mismatch as well as a qualitative mismatch-for instance in the divergence between the university's research portfolio and the private sector's research agenda. Opportunities for more applied (or relevant) research may bring in much needed funding for institutions that are not capable of securing large-scale grants, but it also forces them to sacrifice the traditional notions of what kinds of science are performed within universities.

On the education side, pressures to adjust curricula to better meet the local economy's needs may run counter to the institution's preference (or need) to draw in a more national 
or even international clientele. Accreditation criteria for the degree programs offered often see very little attention paid to community engagement.

Aligning the institutional mission with the demands of external communities would require close interaction between the university and its stakeholders. Today, many universities have a great deal of autonomy when it comes to carrying out their public responsibilities in terms of education and research. Some operate in a supply-driven fashion, dominated by the disciplines, while others are more led by external demands.

Ad 2. Another institutional barrier to strengthening community interaction is connected to the reward system of academics and lecturers. Firstly, the funding parameters that determine the public budget often do not include rewards for regional engagement or community interaction. Secondly, criteria for the assessment of academic research still largely incorporate the traditional academic criteria determined by the academic community. An academic's chances of getting a salary increase or promotion will often be centred on his/her research production in terms of refereed publications or the volume of competitive grants brought in from research councils. The criteria largely do not take into account engagement with non-academic communities. This publish or perish culture may be found in the prestigious universities. In the more teaching oriented institutions it is the lecturer's workload and responsibilities in terms of teaching, and not necessarily the extent of an academic's community engagement, that determine the terms of employment, salary and promotion opportunities.

Ad 3. The lack of entrepreneurial culture in academia is a third barrier to a lively interaction with business and industry. Whereas the previous two barriers mentioned tend to focus on the level of the institution as a whole and touch on aggregate metrics, typologies of transactions and structural approaches, we now turn to the individual level-that is the individual academic and the individual university manager. How have they approached the demands placed on them to become more involved with external communities? According to Gunasekara (2006), theorization on the topic of dilemmas surrounding regional engagement has neglected the individual level of analysis. Apart from the institutional dilemmas already discussed under the previous two headings, the study points to dilemmas related to individual identity issues, notably the role of academic staff in universities and perceived threats to these roles. Several academic staff defined their identity as characterized by an independence of thought and action and do not want to be driven by external demands in the sense of consulting or contract opportunities. Community engagement was seen by them as conflicting with existing norms, including cultural ones (Gunasekara 2006, p. 160). They feel that research commercialisation is not a part of their job as an academic researcher. The same may hold for lecturers. They may be more interested in transferring textbook knowledge to students instead of teaching them the wider potential of knowledge.

Siegel et al.'s (2003) study of university-industry technology transfer found that, in some cases, academics had a poor understanding of the technology process and had little interest in dealing with private companies. Many academic researchers are unaware of the commercial potential of their research findings or lack the required business attitude to develop their concepts and ideas further into products or prototypes. Lee's (2000) study of collaborative relationships between universities and industry found that the primary motivator for academics was alignment with their own research agendas, rather than entrepreneurship, outreach or improved pedagogical practice.

All this means that the undertaking of a third role of community engagement is still obstructed by many institutional barriers, implying that the acceptance of a third mission is not a straightforward action. 


\section{On governance, accountability and corporate social responsibility}

The acceptance of a third mission by universities places additional weight on their shoulders. As stated by Watson (2003), universities are expected to be excellent and relevant (in their teaching and research); to be entrepreneurial and caring (in their approach to students, communities), to be competitive and collegial (in dealing with other knowledge providers); and to be local and international in focus (in teaching and research) at the same time. Thus, universities these days have very many stakeholders and potential partnerships. Thinking in terms of partnerships with stakeholders has a number of important repercussions on the university, its governance and the way in which it fulfills its accountability requirements. Let us now carefully construct our argument here, which is inspired by the work of the Dutch Social Economic Council (SER 2005).

First, we acknowledge that higher education institutions have a public mission. This means: they produce services that produce benefits to the wider society and, because of that, are funded (at least partially) from the public purse. Moreover, the government imposes some standards with respect to the quality of the services provided and the access to the services. However, to a large extent the state will leave a large degree of freedom to the universities to determine the contents of teaching and research. The academic professionals are granted considerable room to realise their ambitions within the framework set by the state. From the 1980s onwards, the neo-liberal steering philosophy that many states adopted to realise reforms and cutbacks in sectors consisting of organisations with a public mission has meant that the state stepped back from micromanaging these sectors. In this climate of deregulation, universities were placed further away from the state. This has had implications for their legitimacy. One may say that when the role of government in terms of financing and regulating is diminishing, the university as a public institution will have to seek its legitimacy in the way and extent to which its services are accepted and valued by its various stakeholders in society. Universities earn and maintain their social legitimacy through the ways and means of quality assurance and the mechanisms through which they are accountable to their clients. In doing this they gain trust.

The need for building trust and being socially accountable is in particular urgent in situations characterised by marketisation, deregulation and decentralisation. In times like this, it is no longer enough to show excellence in the traditional (i.e. academic) sense of the word. The universities' strive for excellence is gradually complemented-some will even say overtaken-by their search for relevance. Increasingly universities are asked to prove their contribution to the knowledge society and to have their teaching and research play a more visible role in strengthening the innovative capacities of the economy. This trend undeniably is part of a general trend towards what may be called accountable governance (Considine 2002). By this we allude to the fact that universities are not only expected to act responsibly (i.e. pay attention to democratic and ethical values), deliver value for money (and improve performance where possible), but also to work on their corporate social responsibility.

The terms corporate responsibility and corporate social responsibility (CSR) are frequently used in discussions about business companies' efforts to develop socially and environmentally aware practices and policies. In a broader sense, CSR may be understood as the need for organisations to consider the good of the wider communities, local and global, within which they function in terms of the economic, legal, ethical and philanthropic impact of their way of conducting business. In higher education, CSR amongst other things relates to universities contributing to the solving of important problems faced by our society_-problems that call for innovation of various kinds: social, economical and 
cultural. One may argue that in such an environment, universities can only secure their claims on the public purse (and thereby generate private support) by acting in ways conforming to notions of CSR.

If universities wish to act in line with this definition of CSR, this is not a matter of vertical control alone. Surely, control is a crucial issue in designing coordination mechanisms for situations where the government 'steers from a distance'. For higher education, vertical control then relates to the mechanisms that, for instance, a minister of education uses to oversee the activities. In (higher) education, there will always be a role for the parliament or education minister in guaranteeing that public goods like access, quality and efficiency are not neglected by the publicly supported institutions. (We can also refer to the role of an Inspectorate or a similar oversight agency here.) However, there are other forms of control and oversight. And where government has stepped back, other forms and agencies of control have come to the fore. Some may even argue that the net effect of this has not been less but more interference. We would be going beyond the boundaries of this article if we were to discuss the pros and cons of the various forms of control here. However, we do want to stress that for organisations that produce public goods it is important that control along vertical lines is always balanced with mechanisms ensuring horizontal accountability. The environment-the stakeholders, or communities-is by definition important for any organisation that has a public mission.

Real commitment to stakeholders is more than just maintaining contacts with clients. It extends to the organisation seeking and using ways of engaging in a dialogue with its various stakeholders in order to learn about how its services are valued and how and where it can do better. Horizontal accountability includes mechanisms to ensure transparency about choices made and communicating the performance of the organisation. The word horizontal stresses the fact that the universities not just render proof of their performance to a principal that is placed higher up in the hierarchy, but to all groups, bodies, agents that have an interest in the universities' operations - that is: their stakeholders. There are various interest groups that may be identified (see Table 2). Therefore, how the horizontal accountability is shaped will depend on the type of stakeholder in question, that is: their degree of importance or salience.

After identifying the stakeholders and the degree of commitment to them, the next step is to determine how the university can build lasting relationships with its key stakeholders. Relationships with stakeholders may be manifested in the university's governance structure. An example is having representatives from communities in decision making bodies. Doing this is not just a matter of efficiency or effectiveness, but also a matter of democracy. One obvious form of horizontal accountability to the wider community is annual reporting. A less common form is through organising debates between members of the internal communities and representatives of external communities. More formal arrangements for showing engagement with communities are through contracts and agreements. In this way, relations between universities, public sector funding bodies and external communities are reorganized in terms of customer-contractor relations. Other forms of horizontal accountability are installing platforms and advisory bodies for consultations with stakeholders, or agreeing on procedures for the handling of complaints and disputes.

For universities, the instrument of peer review is a familiar way of making the relative performance more transparent and thereby responding to demands for horizontal accountability. Peer reviews may be extended beyond the familiar evaluations in which academics from other universities judge the quality of teaching and research in some university department. An option is to extend the composition of the review teams and 
Table 3 The Warwick model of competing paradigms of governance

\begin{tabular}{|c|c|c|c|}
\hline & $\begin{array}{l}\text { Traditional public } \\
\text { administration }\end{array}$ & New public management & Networked governance \\
\hline Context & Stable & Competitive & Continuously changing \\
\hline Population & Homogeneous & Atomized & Diverse \\
\hline $\begin{array}{l}\text { Needs/ } \\
\text { problems }\end{array}$ & $\begin{array}{l}\text { Straightforward, defined by } \\
\text { professionals }\end{array}$ & $\begin{array}{l}\text { Wants, expressed through the } \\
\text { market }\end{array}$ & $\begin{array}{l}\text { Complex, volatile and } \\
\text { prone to risk }\end{array}$ \\
\hline Strategy & State- and producer-centred & Market- and consumer-oriented & Shaped by civil society \\
\hline $\begin{array}{c}\text { Governance } \\
\text { through... }\end{array}$ & Hierarchies & Markets & $\begin{array}{r}\text { Networks and } \\
\text { partnerships }\end{array}$ \\
\hline Actors & Public servants & $\begin{array}{l}\text { Purchasers and providers, clients } \\
\text { and contractors }\end{array}$ & Civic leaders \\
\hline
\end{tabular}

Source: Benington (2005)

include representatives from other communities, or to have peer review teams/panels judge the quality of the non-academic areas of university activity (e.g. community services, technology transfer, student services, etc.). The latter may lead to a kind of benchmarking exercise where different universities learn from each other. Surely, if the outcomes of peer reviews or benchmarking are used to deduce budgets for the university the chances are that the (horizontal) accountability function may suffer. All of this illustrates that more research is needed on the design and working of new mechanisms for horizontal accountability.

Our message is that in a higher education system that produces public goods and is characterized by volatility and unpredictability in terms of demands it is worth exploring how the institutions in their management and primary processes can place their stakeholders in a more central position. As far as the governance of such a system is concerned one may explore the concept of networked governance (Benington 2005) to balance the needs of a diverse set of communities/stakeholders. Networked-or citizen-centredgovernance would help avoid both government failure and market failure, which are accompanying bureaucracies, respectively markets (Table 3).

In discussions on the 'proper management model' for higher education it is easy to concentrate on the managers and the leadership of academia. However, one will have to realize that it is the academics (higher education's core community) that play an important role in running the system - they perform the core tasks in universities. In any case, further research is needed to explore the effects and design of different governance models-or the proper mix of models. To a large extent, many of these questions will be of an empirical character, but conceptual work on concepts like networked governance and horizontal accountability will be equally important.

\section{Conclusions and suggestions for further research}

As their set of stakeholders expands, so too has society's expectations of what the universities' public obligation is. If we take a leap through history, from the days of the early universities that provided education for the church and other elites to the present times of massified higher education systems, we may conclude that higher education has become inextricably linked to the notion of progress both at an individual and a societal level. The spread and democratization of higher education means that many organizations and 
individuals have a stake in higher education and want to have their say. In this sense, Benneworth and Arbo argue:

the institutions are becoming more socially embedded. The consequence is that both the higher education institutions and national governments are facing a growing multitude of expectations. As knowledge is sought for as the solution to everything, demands of the environment are penetrating higher education. Typically, the institutions respond by additive solutions. They are appending new layers of academic specialties, study programmes, services and administrative units to the organization in order to meet the challenges. (Benneworth and Arbo 2006, p. 30).

The reaching out to communities and the taking on of civic responsibilities conforms to a trend to design higher education and science policies in ways that make teaching and research more publicly accountable and relevant to society. New forms of market-based, customer accountability are restructuring the context of degree programs and scientific research and contribute to a reorientation of long standing academic norms and values. These changes are designed to make academic research and curricula more responsive to the demands of various paying customers.

These calls on universities to be responsive and accountable in a more broad way have been discussed at length in this article. We have argued that responding to these calls affects the way in which universities render proof of their excellence and relevance, the way in which they manage and control their internal operations, maintain close links with their stakeholders and develop strategies for their organisation. These days, their corporate social responsibility extends beyond producing graduates and research outputs. It requires them to engage in public debates, to enter into close working relationships with private actors and to be part of multiple networks and alliances with multiple actors on various levels. We have argued here that in today's network society, providers of higher education and lifelong learning will have to be in constant dialogue with their many communities/ stakeholders, including government agencies, students, business, research sponsors, communities and regional authorities. The linking up with external stakeholders and communities is strengthened further by state policies aimed at de-regulation and marketisation.

All of this suggests a challenging agenda for research into higher education. A first question we wish to identify here is of a conceptual nature:

1. How can concepts like stakeholder theory, corporate social responsibility or horizontal accountability be framed for the field of higher education and research?

We have tried to show that theories and concepts developed so far-to understand phenomena taking place in other sectors and organisations, namely in the business worldhelp us to conceptualise the field of higher education as well. Any analogy between the world of higher education and the world of business has, however, potential limits given the multi-functional role of universities as deeply fragmented organisations in the provision of public goods. This calls for a re-framing of existing concepts as well as for the development of new concepts for the study of higher education.

Second, we have argued that the number and variety of external interests with which the higher education institutions deal with, seek support from, and, ultimately, rely upon has literally exploded. This produces the risk of running into problems of 'mission overload'; that universities 'try to be all things to all people'. To fulfil their obligation towards being a socially accountable institution producing public goods therefore urges the universities to carefully select their stakeholders and identify the 'right' degree of differentiation. This 
raises questions about mechanisms of stakeholder identification, governance, management and accountability. It also leads to questions about the design of the interface between the university and its stakeholders-both the external stakeholders and the internal constituencies.

2. Do higher education institutions go about prioritising their different functions and stakeholders and how do they do so? What are the functional and structural add-ons that the institutions may create to handle the growing complexity in terms of stakeholder demands?

Third, for the universities, increased stakeholder involvement and external demand come down to the issue of strategic choice. The issue relates to the changing balance (and sometimes tensions) between the state and the market, the global and the local, the public and the private, massification and individualisation, cooperation and competition, autonomy and accountability. This may not only give rise to tensions within the universities and throughout the academic system at large, but also raises questions on organisational and systemic performance:

3. How do we establish whether higher education and research are actually becoming more 'relevant', more closely linked to societal needs and stakeholder demands? What evidence is there? What indicators are suitable? And what are the costs and benefits in terms of 'old' and 'new' functions of universities?

Earlier we mentioned that when the state steps back the university has to find its own legitimacy in how its services are accepted and evaluated by the various communities in society it seeks to serve. But then the question becomes whether a set of individual institutional selections can deliver the required outcomes of equity and efficiency in the public interest. This does not only lead to performance questions addressed above, but also to questions about the (supervisory) role of the state; how it looks upon the structure of a higher education system characterised by more profiling and specialisation. These are more policy-oriented questions addressing the system level:

4. How can the government, as the body responsible for the overall co-ordination and well-being of the higher education system, best shape its tasks of guaranteeing diversity, access and quality in the academic system?

By identifying these four questions we hope to encourage systematic research on the field of higher education's interaction with society. We believe there is a need for more research in this important area, given the trends to increase the weight of societal interests in higher education and research.

Open Access This article is distributed under the terms of the Creative Commons Attribution Noncommercial License which permits any noncommercial use, distribution, and reproduction in any medium, provided the original author(s) and source are credited.

\section{References}

Alpert, D. (1985). Performance and paralysis: The organizational context of the American research university. Journal of Higher Education, 56(3), 242-281.

Benington, J. (2005). Innovation and improvement in governance and public services. Paper for CIPFA Annual Conference, June 2005. Available at: http://www.cipfa.org.uk/cipfa2005/conference/download/ JohnBenington_WarwickUniWorkshop.ppt (accessed 12 March 2008).

Benneworth, P., \& Arbo, P. (2006). Understanding the regional contribution of higher education institutions: A literature review. Paris: OECD/IMHE. 
Burrows, J. (1999). Going beyond labels: A framework for profiling institutional stakeholders. Contemporary Education, 70(4), 5-10.

Castells, M. (1996). The information age: Economy, society and culture: Vol. 1, The rise of the network society. Oxford: Blackwell.

Charles, D., \& Benneworth, P. (2002). Evaluating the regional contribution of an HEI: A benchmarking approach. Downloadable from: http://www.hefce.ac.uk/Pubs/hefce/2002/02_23.htm (accessed 12 March 2008).

Chatterton, P., \& Goddard, J. (2000). The response of higher education institutions to regional needs. European Journal of Education, 35(4), 475-496.

Clark, B. (1998). Creating entrepreneurial universities: Organizational pathways of transformation. Oxford: Pergamon.

Cohen, W. M., Nelson, R. R., \& Walsh, J. P. (2002). Links and impacts: The influence of public research on industrial R\&D. Management Science, 48(1), 1-23.

Considine, M. (2002). The end of the line? Accountable governance in the age of networks, partnerships and joined-up services. Governance, 15(1).

De Boer, H.F., Enders, J., \& Leisyte, L. (2007). Public sector reform in Dutch higher education: The organizational transformation of the university. Public Administration, 85(1), 27-46.

Dill, D. D., \& Sporn, B. (1995). The implications of a postindustrial environment. In D. D. Dill, \& B. Sporn (Eds.), Emerging patterns of social demand and university reform: Through a glass darkly (pp. 1-19). Oxford: Pergamon Press.

Enders, J. (2004). Higher education, internationalisation, and the nation-state: Recent developments and challenges for governance theory. Higher Education, 47(3), 361-382.

Enders, J., \& Fulton, O. (2002). Blurring boundaries and blistering institutions: An introduction. In J. Enders, \& O. Fulton (Eds.), Higher education in a globalising world: International trends and mutual observations (pp. 1-16). Dordrecht/Boston/London: Kluwer Academic Publishers.

Enders, J., \& Jongbloed, B. (Eds.), (2007). Public-private dynamics in higher education: Expectations, developments and outcomes. Bielefeld: Transccipt Verlag.

Etzkowitz, H., \& Leydesdorff, L. (Eds.), (1997). Universities and the global knowledge economy: A triple helix of university-industry-government relations. London: Cassell Academic.

European Commission (EC) (2003). The role of the universities in the Europe of knowledge. Communication from the Commission. Brussels, 05.02.2003, COM(2003) 58 final.

Freeman, R. E. (1984). Strategic management: A stakeholder approach. Boston, MA: Pitman.

Garlick, S. (2000). Engaging universities and regions: Knowledge contribution to regional economic development in Australia. Canberra: DETYA.

Geiger, R. L. (1993). Research and relevant knowledge. Oxford: Oxford University Press.

Gibbons, M., Limoges, C., Nowotny, H., Schwartzmann, S., Scott, P., \& Trow, M. (Eds.), (1994). The new production of knowledge: The dynamics of science and research in contemporary societies. London: Sage.

Gläser, J. (2000). Limits of change: Cognitive constraints on 'postmodernization' and the political redirection of science. Social Science Information, 39(4), 439-465.

Goddard, J. (1999). The response of higher education institutions to regional needs. Paris: OECD/CERI.

Goddard, J. B., Charles, D., Pike, A., Potts, G., \& Bradley, D. (1994). Universities and communities. London: CVCP.

Gunasekara, C. (2006). Leading the horses to water: The dilemmas of academics and university managers in regional engagement. Journal of Sociology, 42(2), 145-163.

Guston, D. H., \& Keniston, K. (Eds.), (1994). The fragile contract. Cambridge, MA: MIT Press.

Huisman, J., Westerheijden, D., \& de Boer, H. F. (2001). De Tuinen van het Hoger Onderwijs. Scenario's voor 2010. Enschede: CHEPS.

Huyzer, S. E. (1990). Strategische Samenwerking. Alphen aan den Rijn: Samsom.

ILO. (1975). Le Role des Universités dans l'Éducation Ouvrière. Proceedings of the 1973 Colloquium. Geneva: International Labour Organization.

Joanneum Research (2001) (Ed.). Benchmarking industry-science relations-The Role of Framework Conditions. Vienna: Joanneum Research, Austria.

Jongbloed, B. (2006). Academic research in the Dutch delta. Paper for the ARE (Academic Research Enterprise Seminar). Seville (Spain).

Jongbloed, B., \& Goedegebuure, L. (2001). From the entrepreneurial university to the stakeholder university. Paper for the international congress 'Universities and Regional Development in the Knowledge Society. 12-14 November, Barcelona.

Lee, Y. S. (1996). Technology transfer and the research university: A search for the boundaries of university-industry collaboration. Research Policy, 25, 843-863. 
Lee, Y. (2000). The sustainability of university-industry research collaboration: An empirical assessment. Journal of Technology Transfer, 25, 111-133.

Mitchell, R. K., Agle, B. R., \& Wood, D. J. (1997). Toward a theory of stakeholder identification and salience: Defining the principle of who and what really counts. Academy of Management Review, 22(4) 853-886.

Mowery, D. C., Nelson, R. R., Sampat, B. N., \& Ziedonis, A. A. (2001). The growth of patenting and licensing by U.S. universities: An assessment of the effects of the Bayh-Dole Act of 1980. Research Policy, 30, 99-119.

Mowery, D. C., \& Sampat, B. N. (2005). The Bayh-Dole Act of 1980 and university-industry technology transfer: A model for other OECD governments? Journal of Technology Transfer, 30(1/2), 115-127.

Neave, G. (2000). The universities' responsibilities to society. Oxford: Pergamon.

Neave, G. (2006). Redefining the social contract. Higher Education Policy, 19, 269-286.

OECD (2007). Higher education and regions: Globally competitive, locally engaged. Paris: OECD.

OECD-CERI (1982). The university and the community: The problems of changing relationships. Paris: OECD.

Paytas, J., Gradeck, R., \& Andrews, L. (2004). Universities and the development of industry clusters. Report prepared for the Economic Development Administration of the United States Department of Commerce.

Rothblatt, S. (1997). The modern university and its discontents. Cambridge: Cambridge University Press.

Rothschild, M., \& White, L. J. (1995). The analytics of pricing in higher education and other services in which customers are inputs. Journal of Political Economy, 103, 573-586.

Shavit, Y., \& Blossfeld, H. -P. (Eds.), (1993). Persistent inequality: Changing educational attainment in thirteen countries. Boulder, CO: Westview Press.

Shinn, T. (1999). Change or mutation? Reflections on the foundations of contemporary science. Social Science Information, 38(1), 149-176.

Siegel, D. S., Waldman, D., \& Link, A. N. (2003). Assessing the impact of organizational practices on the productivity of university technology transfer offices: An exploratory research. Research Policy, 32(1), $27-48$.

Sociaal-Economische Raad (SER) (2005). Advies Ondernemerschap voor de Publieke Zaak (Entrepreneurship for the public good). Advies 05/04. Den Haag: Sociaal Economische Raad.

Tight, M. (Ed.), (2003). Access and exclusion. Amsterdam et al.: Elsevier.

Trow, M. (1996). On the accountability of higher education in the United States. In P. A. M. Maassen, \& F. A. van Vught (Eds.), Inside academia: New challenges for the academic profession (pp. 227-268). Utrecht: De Tijdstroom.

Watson, D. (2003). Universities and civic engagement: A critique and a prospectus. Paper for the 2nd biennial "inside-out" Conference, University of Queensland.

Weingart, P. (1997). From 'Finalization' to 'Mode 2': old wine in new bottles? Social Science Information, 36(4), 591-613.

Winston, G. C. (1999). Subsidies, hierarchy and peers: The awkward economics of higher education. Journal of Economic Perspectives, 13, 13-36. 